\title{
PROPOSTA DE JOGO EDUCATIVO PARA A EDUCAÇÃO AMBIENTAL NO ENSINO BÁSICO
}

Francisco Giovani Souza Laércio ${ }^{1}$

Letícia Rodrigues da Fonseca²

Resumo: Propor uma ferramenta pedagógica para a Educação Ambiental (EA) no Ensino Básico foi o objetivo do presente estudo. Para isso, desenvolveu-se um jogo educativo digital no formato de um quiz, submetido para o uso de alunos do Ensino Fundamental II de uma Instituição de Educação Básica Pública do Estado de São Paulo. Após a aplicação do jogo em duas etapas, evidenciou-se uma melhoria no desempenho dos alunos, pois por meio da avaliação dos erros e acertos foi possível aprender, principalmente, quando o jogo e o professor apresentavam as justificativas para as questões incorretas e corretas. Constatou-se que os alunos visualizam os jogos como ferramentas que promovem a aprendizagem significativa e ativa.

Palavras-chave: Educação Ambiental; Educação Básica; Jogos Digitais.

Abstract: Proposing a pedagogical tool for Environmental Education (EE) in Basic Education was the objective of this study. For this, a digital educational game was developed in the form of a quiz, submitted for the use of students from Elementary School II of a Public Basic Education Institution in São Paulo. After the application of the game in two stages, there was an improvement in the performance of the students, because through the evaluation of mistakes and successes it was possible to learn, mainly, when the game and the teacher presented the justifications for incorrect and correct questions. It was found that students view games as tools that promote meaningful and active learning.

Keywords: Environmental Education; Basic Education; Digital Games.

\footnotetext{
1Universidade Vale do Rio Verde (UninCor). E-mail: ghighio@uol.com.br, Link para o Lattes: http://lattes.cnpq.br/2709840651848020

2 Universidade Vale do Rio Verde (UninCor). E-mail: leticia.rodrigues.vga@gmail.com, Link para o Lattes: http://lattes.cnpq.br/4847209046603133
} 


\section{Introdução}

A escola é um espaço voltado para a formação de indivíduos críticos que sejam capazes de identificar e propor soluções para os problemas que afetam a sociedade, inclusive, aqueles no âmbito ambiental. Logo, cabe às Instituições de Ensino estabelecer e aplicar metodologias que possibilitem a abordagem da Educação Ambiental (EA) conforme os princípios da aprendizagem significativa. Dessa forma, os alunos conseguirão compreender a sua importância e adotarão um comportamento voltado para a preservação ambiental que influencie, inclusive, os demais indivíduos presentes nos contextos sociais em que estão inseridos (POLLI; SIGNORINI, 2012)

Os conteúdos que atendem aos objetivos de aprendizagem da EA são ministrados de maneira transdisciplinar, conforme proposto pelas diretrizes curriculares para a educação básica. As práticas pedagógicas utilizadas para expor estes conteúdos buscam a sensibilização e análise crítica dos educandos em relação aos conflitos socioambientais nos níveis mundial, estadual e local, além de discutir os diferentes paradigmas ambientais para que os alunos possam construir a sua própria opinião.

Para isso, algumas ferramentas e estratégias de ensino podem ser utilizadas como palestras, oficinas, estudos de caso, jogos educativos, entre outras metodologias que levem à reflexão e ao aprendizado significativo por meio da prática, além de possibilitarem a inclusão dos educandos como parte do meio ambiente, transformando-os em sujeitos multiplicadores (CUNHA; MOTA, 2018).

Sabe-se que os avanços tecnológicos vêm promovendo mudanças e impactando a rotina dos sujeitos que vivem em sociedade, inclusive daqueles que interpelam o contexto educacional (OLIVEIRA; MORAES, 2019). Este, cada vez mais digital, vem demandando por práticas inovadoras e mudanças de paradigmas no âmbito do processo ensino-aprendizagem (VALENTE; ALMEIDA; GERALDINI, 2017) que envolvem o uso de ações pedagógicas e metodologias mais efetivas, dinâmicas e condizentes com a realidade dos educandos (VASCONCELLO et al., 2017).

Devido a este avanço da tecnologia, os jogos digitais têm sido utilizados cada vez mais na educação básica como uma ferramenta para o atendimento dos objetivos de aprendizagem de diversas disciplinas. $O$ ato de jogar é considerado uma atividade que motiva o aprendizado de uma forma lúdica e didática, favorecendo o pensamento cognitivo, o raciocínio lógico e a construção de conhecimentos. Ao apresentarem cenários semelhantes à realidade dos alunos e situações que necessitam de soluções para determinados problemas, os jogos educacionais favorecem o desenvolvimento de competências, habilidades e atitudes que permitirão aos educandos agirem em prol da preservação ambiental, desde que ocorra a sua sensibilização e conscientização. 
Sabe-se que os avanços tecnológicos utilizados na EA vêm modificando o processo de aquisição do conhecimento, estando este focado em quem aprende, dissociando-se das estratégias utilizadas por quem ensina (PINHEIRO; OLIVEIRA NETO; MACIEL, 2021). A aquisição do conhecimento vem assumindo um processo de (re)construção efetiva da teoria que se sabe e da prática para o que necessita saber (BACICH; MORAN, 2018).

A metodologia de Aprendizagem Baseada em Jogos (ABJ) - ou Game Based Learning (GLB) (PRENSKY, 2012) - visa proporcionar ambientes críticos e que possam conduzir os 'aprendentes' à construção do conhecimento, a partir de situações prazerosas e lúdicas de desenvolvimento da cognição (BRAGA; COSTA. 2017) e, no contexto da EA, aposta-se no uso de jogos digitais com esta finalidade (PINHEIRO; OLIVEIRA NETO; MACIEL, 2021).

Diante do contexto apresentado este estudo propôs, como objetivo geral, propor uma ferramenta pedagógica para promover a EA no ensino básico. Por sua vez, como objetivos específicos: desenvolver um jogo educativo que favoreça a EA no ensino básico; e obter evidências acerca da efetividade deste jogo no processo de ensino-aprendizagem.

\section{Educação Ambiental}

O termo 'ambiental', quando associado à educação, tem representatividade histórica e se desenvolveu na condição de buscar respostas às crises ambientais em conjunto com o surgimento de novos valores éticos relacionados às crises (SOUZA, 2020).

Nas escolas, a associação dos termos - então, a Educação Ambiental trouxe a promessa de ajuda às pessoas para o enfrentamento instrumentado da realidade, por meio de ações reflexivas sobre os fenômenos sociais. Assim, as expectativas da sociedade brasileira para com a escola geraram respostas à crescente disseminação de sua proposta. Considerando os diversos conceitos atribuídos à EA, interessa aquele que oportuniza aos sujeitos compreender, de forma crítica e global, o ambiente para que possa priorizar valores e, a partir daí, desenvolver atitudes responsivas por meio da conscientização e da participação em questões relacionadas à conservação e ao uso adequado dos recursos naturais - tendo como resultante, a melhoria da qualidade de vida, erradicação da pobreza e do consumo desenfreado (PINHEIRO; OLIVEIRA NETO; MACIEL, 2021).

A EA foi incluída no currículo escolar desde os Parâmetros Curriculares Nacionais (PCN) no ano de 1999, subsidiada pelo Programa Nacional de Educação Ambiental (ProNEA) e pela Política Nacional de Educação Ambiental - na forma da Lei 9.795/99 (SANTOS et al., 2020). Em 2012, as Diretrizes Curriculares Nacionais para a EA (DCNEA) foram aprovadas e homologadas, materializando um documento que contempla exigências constitucionais, principalmente em seus artigos 22 e 210 que estabelecem bases para

revista brasileira educação ambiental 
orientações, articulações e desenvolvimento da educação básica nacional, vindo regular o ensino (OLIVEIRA; NEIMAN, 2020). Deste então, a EA se faz um componente educacional que deve constar em todos os níveis e modalidades de ensino (SANTOS et al., 2020).

Entretanto, a reformulação do Ensino Fundamental e Médio proposta pelo governo no período de 2017-2018 veio implantar a nova Base Nacional Curricular Comum (BNCC), sendo que os temas transversais - inclusive a EA não estão contemplados explicitamente. Desde então, especificamente em relação ao Ensino Fundamental, os educandos vêm se deparando com a complexidade gradativa dos assuntos relacionados à EA a serem estudados (OLIVEIRA; NEIMAN, 2020).

A Educação Ambiental, hoje, apresenta-se como uma das estratégias que pode contribuir na formação de cidadãos ativos em relação a sua realidade. $O$ processo de aprendizagem que a envolve deve ser centrado no aluno, gradativo, contínuo e respeitador de sua cultura e sociedade. Deve ser um processo crítico, criativo e político, com a preocupação de construir conhecimentos a partir da discussão e envolvimento com os processos avaliativos dos problemas comunitários, assim como do olhar observador dos estudantes que, como protagonistas exercem um importante papel de sensibilização social por meio de uma realidade individual e coletiva na comunidade em que vivem, fruto das percepções e vivências apreendidas cotidianamente, fator que gera resultados positivos a curto e longo prazo (SILVEIRA; RUAS; ELIAS, 2020, p.107).

Tal exigência busca a consolidação da autonomia dos educandos e, para êxito, requer a adoção de ferramentas metodológicas que possam ajudar efetivamente no processo de aprendizagem significativa - principalmente por meio de ferramentas que priorizem o protagonismo dos educandos no desenvolvimento de seu processo crítico-reflexivo. Dentre as ferramentas metodológicas disponíveis, a tecnologia vem sendo enaltecida (OLIVEIRA; NEIMAN, 2020).

As escolas passaram a abordar a EA em seus planos de ensino com o intuito de contribuir na construção de valores que levem os seus educandos à convivência harmoniosa e respeitosa com o outro e com o ambiente - desta forma, desenvolvendo o pensamento de pertença, caracterizado como aquele de 'ação local e pensamento global'. Os educandos podem adquirir, assim, olhares para uma construção crítica frente aos atos impensados e inconsequentes que possam levar ao uso dos recursos naturais de forma desenfreada (SOARES; NASCIMENTO, 2020).

De acordo com Silveira, Ruas e Elias (2020), para que esta EA pretendida ocorra é necessário o envolvimento da escola em práticas 
educativas que venham suprir reflexões entre os educandos e a sociedade. A escola se faz, desta forma, espaço primordial e prioritário para a construção de pensamentos crítico-reflexivos, de desenvolvimento de atitudes responsivas e habilidades protetivas para com o meio ambiente. Constitui-se, em suma, como um espaço propenso para o desenvolvimento de valores e conceitos morais, sociais e éticos dos sujeitos que vivem em sociedade, para a convivência harmônica com seu semelhante e com o meio.

A Educação Ambiental na Educação Básica deve ser vista pela escola como um processo essencial, pois o ambiente escolar ajuda a desenvolver os valores morais e éticos do indivíduo, inclusive com relação ao meio ambiente. Além disso, as crianças e os adolescentes ainda estão construindo sua identidade, o que implica são os valores e as direções que desejam seguir pela vida. Essa fase de construção é fator de vantagem para torná-las cada vez mais conscientes (SOARES; NASCIMENTO, 2020, p.113).

Souza (2020) afirma que, dentro desta proposta de EA construtiva, o Ensino Fundamental apresenta-se como a etapa mais complexa do desenvolvimento curricular pois os educandos recebem uma diversidade de conceitos para se tornarem cidadãos éticos. De acordo com Soares e Nascimento (2020, p.113), esta etapa "destaca-se por possibilitar a sensibilização quanto às questões ambientais e permitir a discussão dos alunos sobre elas, trazendo a conservação do meio ambiente para o cotidiano do processo de geração de conhecimentos".

Diante desta realidade, é emergente a adoção de diferentes e efetivas metodologias para o êxito das metas de formação de educandos nesta etapa da educação básica. Faz-se consenso a afirmativa de que as metodologias devam ultrapassar as formas tradicionais de ensino (SOARES; NASCIMENTO, 2020; OLIVEIRA; NEIMAN, 2020; SOUZA, 2020; SILVEIRA; RUAS; ELIAS, 2020; PINHEIRO; OLIVEIRA NETO; MACIEL, 2021). Logo, a tecnologia apresenta-se como o recurso ideal para a nova geração de educandos segmentada como nativos digitais (MORAN; MASETTO; BEHRENS, 2013; BRAGA; COSTA, 2017; RAMOS; CRUZ, 2018; SANTOS et al., 2020).

O uso das tecnologias em sala de aula para a efetivação da EA pode acontecer por meio da gamificação (ou dos jogos digitais), com o intuito de ocasionar a mudança de comportamento almejada para os alunos com vistas à formação de atitudes responsivas sustentáveis. Portanto, apresenta-se como uma alternativa para aproximar os conteúdos relacionados ao Ensino Fundamental com a realidade dos educandos desta nova geração (SOARES; NASCIMENTO, 2020; OLIVEIRA; NEIMAN, 2020; SOUZA, 2020; SILVEIRA; RUAS; ELIAS, 2020; PINHEIRO; OLIVEIRA NETO; MACIEL, 2021). 


\section{Aprendizagem Baseada em Jogos}

Os jogos sempre estiveram presentes na sociedade e, desde a antiguidade, foram praticados por adultos e crianças. Contudo, eram concebidos somente como atividade física a ser praticada para a promoção da diversão e do bem-estar (KAMII; RHETA, 2009). Aos poucos e apoiando-se em resultados de pesquisas anteriores, os jogos passaram a ser concebidos como uma proposta para o desenvolvimento intelectual e social, especificamente como uma metodologia (KISHIMOTO, 2000) para a promoção da aprendizagem significativa (SANTOS et al., 2020).

Kamii e Rheta (2009) fizeram um resgate conceitual acerca da importância e proposta educacional cronológica dos jogos e citaram como principais estudiosos/pensadores: Jean-Jacques Rousseau (1712-1778) - que propunha a educação interpelada pela natureza e apresentava os jogos desportivos como instrumentos; Friedrich Froebel (1782-1852) - acreditava que os jogos representavam atividades de expressão da criatividade e demonstração da consciência da relação tempo versus espaço; Édouard Claparède (1873-1940) - concebia os jogos como modelos/instrumentos para a educação; John Dewey (1859-1952) - defendia a aprendizagem por meio de propostas e experiências ativas, caracterizando os jogos com uma de suas formas; Ovídio Decroly (1871-1932) - responsável pela proposta formalizada de jogos educativos; Cousinet (1881-1973) - fundador da Escola Nova, apostou nos jogos como base para seu método pedagógico; Jean Piaget (1896-1980) - estudioso que concebeu os jogos como forma de ajuda e meio para a promoção do desenvolvimento cognitivo e social da criança.

Ainda no contexto de tal resgate conceitual sobre os jogos, faz-se necessário destacar o apontamento de Vygotsky (2003), de que a promoção do raciocínio lógico está articulado à relação dos jogos com a ampliação da zona de desenvolvimento proximal (ZDP) do 'aprendente', haja vista que seu uso vem trazer benefícios sociais, cognitivos e afetivos, além de trabalhar questões importantes como a imaginação/criação, a ludicidade, a imitação e o respeito às regras.

E, dentro da proposta de aprendizagem significativa a partir dos jogos, a educação vem se favorecendo por meio de distintas estratégias metodológicas impactantes no ensino e na aprendizagem de crianças e adolescentes. A ascensão da cultura digital e os aparatos tecnológicos integrados à internet tornaram-se parte do processo educativo - em nível curricular e em nível dos sujeitos envolvidos. E, dentro das possibilidades de integrar tecnologia e educação, os jogos digitais despontaram-se como potencialmente estratégicos, inclusive para a promoção da EA (SILVA et al., 2020), considerando que alguns games são capazes de sensibilizar sujeitos com o intuito de levá-los a se tornarem cidadãos melhores e mais responsáveis (McGONIGAL, 2017). 


\section{Jogos digitais educativos}

A associação das tecnologias da informação e comunicação com o contexto educacional não se deu de forma isolada, mas devido a relação mantida ao longo do tempo pelos indivíduos com tais tecnologias em diferentes contextos (ALVES, 2013).

Desta forma, de acordo com Prensky (2010), não se pode negar o poder das tecnologias de informação e comunicação no âmbito do ensino. Por meio de recursos tecnológicos o ser humano aprimorou suas formas de relacionamento com seus pares e com o meio sociocultural em que está inserido.

Ramos e Cruz (2018) afirmam que os jogos digitais surgiram em um contexto em que se fez emergencial o uso de recursos para despertar a atenção de crianças, jovens e adultos, sendo cumprida a sua função por meio da instigação e de desafios que requerem soluções. Para Mattar (2010), os games são um marco no qual a educação foi desmistificada como um processo isolado, ocasionando a evolução necessária para acompanhar os sujeitos midiáticos.

Assim, os jogos digitais passaram a ser conceituados como games habilitados para transportar jogadores, de todas as idades, para o meio eletrônico, para o desenvolvimento de habilidades, promoção de interação imediata, produção e recebimentos de informações/conhecimentos automatizados e comunicados em rede (PAULA; VALENTE, 2016; MORAN; MASETTO; BEHRENS, 2013).

Ao assumirem a caracterização de 'educativos', começaram a ser inseridos nos contextos de aprendizagem (MATTAR, 2010). Pelas características centrais dos jogos de desafio e interatividade (BRAGA; COSTA, 2017), ficou entendido que estes seriam uma forma significativa de promover o desenvolvimento de habilidades cognitivas, necessárias para a resolução de problemas, formulação de estratégias e pensamento lógico para tomadas de decisões - imprescindíveis no processo de ensino-aprendizagem (ALVES, 2013).

Devido a tais constatações, Mattar (2010) e Prensky (2012) afirmam que os jogos digitais educativos são recursos excepcionais para a promoção da aprendizagem, principalmente, porque o retorno do processo é percebido de maneira imediata, obtendo-se uma avaliação diagnostica pontual, sendo possível perceber as habilidades desenvolvidas (ou não).

Em colaboração com os autores, Ramos e Cruz (2018) defendem a conciliação de jogos digitais com a educação para favorecer a motivação no âmbito escolar, ao considerar as necessidades da educação contemporânea e a existência de sujeitos digitais (OLIVEIRA; MORAES, 2019).

Em termos estratégicos, a aprendizagem baseada em jogos é uma forma de 'educomunicação' que possibilita: interações entre os pares 
envolvidos (docente-discentes; discentes-discentes), construção de valores comuns, respeito às regras e desenvolvimento de trabalhos colaborativos (ou em grupo), competividade saudável em forma de desafios a serem vencidos (COUTINHO; ALVES, 2016).

O objetivo dos jogos digitais na educação é promover aulas com conteúdos mais dinâmicos e atrativos, motivando sujeitos desinteressados ou apáticos na sala de aula. Entretanto, sua efetividade requer o estabelecimento de regras e formas de jogar, além de planejamento didático-pedagógico. A avaliação também faz parte do processo, ocorrendo de maneira participativa, em que os alunos são conscientizados acerca das consequências e decisões tomadas nos jogos, bem como, são responsabilizados pela produtividade e qualidade obtidos ao jogar (FERNANDES; LUCENA; ARANHA, 2018).

Dentre as modalidades disponíveis de jogos categorizados como educacionais, tem-se os jogos sérios (ou, comumente conhecidos como jogos de aprendizagem) - em que se enquadra os jogos digitais. Esta modalidade é caracterizada pela promoção de concentração (capacidade analítica e capacidade de pensamento) e pela liberdade de escolha (regida pelo domínio emocional e análise crítica) (FERNANDES; LUCENA; ARANHA, 2018).

Paula e Valente (2016), descrevem as vantagens dos jogos educacionais, sendo: despertam maior interesse pelos conteúdos contemplados; facilitam a introdução de conteúdos mais complexos, bem como, o desenvolvimento de habilidades; ampliam as estratégias e a formulação de hipóteses para resolução de problemas e definição de propostas de solução; possibilitam a avaliação dos resultados a partir das respostas demandadas; promovem interdisciplinaridade; promovem socialização e trabalho/tarefa em equipe e; exercitam e desenvolvem o raciocínio lógico e pensamento crítico.

Ramos e Cruz (2018) ressaltam que, apesar da evolução tecnológica que permeia a sociedade e todo o seu contexto, incluindo o educacional, ainda é grande o número de docentes que não reconhecem ou rejeitam o uso desta metodologia inovadora na sala de aula, em todos os níveis de ensino. Logo, a capacitação é necessária para que os educadores possam perceber a potencialidade dos jogos educativos no processo de ensino-aprendizagem (BRAGA; COSTA, 2017).

\section{O Quiz Digital para promoção da Educação Ambiental}

A EA envolve conceitos que demandam por ações que permitam contextualizá-los para se obter êxito em suas propostas e atender os seus objetivos de aprendizagem. Considerando sua característica conceitual, atividades que promovam desafios podem se constituir excelentes estratégias para o seu desenvolvimento - como é o caso dos jogos, precisamente, os jogos digitais (SOARES; NASCIMENTO, 2020). 
Um dos gêneros mais populares e conhecidos que exploram a aprendizagem de fatos e conceitos é o 'quiz', geralmente construído por meio de desafios de perguntas e respostas, possibilitando competir com outros jogadores para alcançar melhores resultados (RAMOS; CRUZ, 2018, p. 23).

Soares e Nascimento (2020) afirmam que é grande a demanda por jogos digitais enquanto estratégias para a EA - principalmente no Ensino Fundamental. Os autores acrescentam que a EA requer uma aprendizagem conceitual. Neste sentido, de acordo com Ramos e Cruz (2018), o 'quiz digital' apresenta-se como uma excelente estratégia (PEREZ; BOTINO, 2020).

O uso do Quiz em sala de aula, aliado às novas tecnologias, é uma estratégia útil no processo de ensino-aprendizagem [...], tornando os conteúdos abordados mais atrativos ao aluno, podendo ser aplicado em qualquer disciplina. Hoje existe uma enorme variedade de ferramentas didáticas que possibilitam a criação de Quizes adaptados a diferentes propósitos. O Quiz não precisa se restringir a um jogo de perguntas e respostas, podendo ser complementado, por exemplo, com imagens, vídeos e situações-problemas (PEREZ; BOTINO, 2020, p.1).

Ferreira e Oliveira (2021) destacam que o quiz digital pode promover a revisão de conteúdos e a aquisição de novos, de forma lúdica e desafiadora, por meio de interação e repetição. Sendo assim, de acordo com Soares e Nascimento (2020), o quiz possibilita revisar, fixar e exercitar conteúdos da EA, favorecendo sua aprendizagem de forma significativa. Para Coutinho e Alves (2016), o quiz é um game que, em formato digital, exercita a atitude e as ações intencionais para alcançar um objetivo concreto que é sempre a resposta assertiva e, por isso, quando à serviço da EA, faz-se promissor no processo de mudança de comportamento (socioambiental).

Em consenso, autores afirmam que o uso do quiz em formato digital é uma alternativa para o aprofundamento, consolidação e reforço de conteúdos e conceitos e, principalmente, uma alternativa para avaliação da aprendizagem. Este recurso objetiva incentivar os estudantes à reflexão acerca de conteúdos de ordem teórica e prática, abordados em sala de aula (COUTINHO; ALVES, 2016; RAMOS; CRUZ, 2018; PEREZ; BOTINO, 2020; FERREIRA; OLIVEIRA, 2021).

Ainda, em relação à proposta de avaliação exercitada pelo quiz, Gossenheimer, Carneiro e Castro (2015) ressaltam a sua característica formativa - ou seja, possibilitam a realização de avaliações acerca do progresso acadêmico do estudante, bem como, evidenciam a necessidade de reforços na aprendizagem por meio da identificação de conceitos que ficaram deficitários ou de habilidades e competências que não foram desenvolvidas de maneira satisfatória. 


\section{Procedimentos metodológicos}

Esta pesquisa é caracterizada como do tipo aplicada, por fazer uso de teorias, técnicas e ferramentas para o desenvolvimento de uma solução caracterizada como um produto técnico-tecnológico que foi aplicado em um determinado contexto para atender um propósito específico (YIN, 2005).

Pode ser caracterizada ainda como exploratória e descritiva e de abordagem qualitativa, por analisar resultados de aprendizagem e relatos dos alunos do ensino básico que participaram desta investigação, com o intuito de se obter evidências acerca da efetividade deste jogo educativo no processo de ensino-aprendizagem (GODOY, 1995).

Este trabalho foi desenvolvido na Escola Estadual "Coronel Horta" (Figura 1) em uma unidade escolar localizada no município de Lavrinhas, Estado de São Paulo, localizado de acordo com as seguintes coordenadas geográficas latitude: 22은 35 e longitude: 44 5615 W. O município apresenta uma área total de $167 \mathrm{~km}^{2}$.
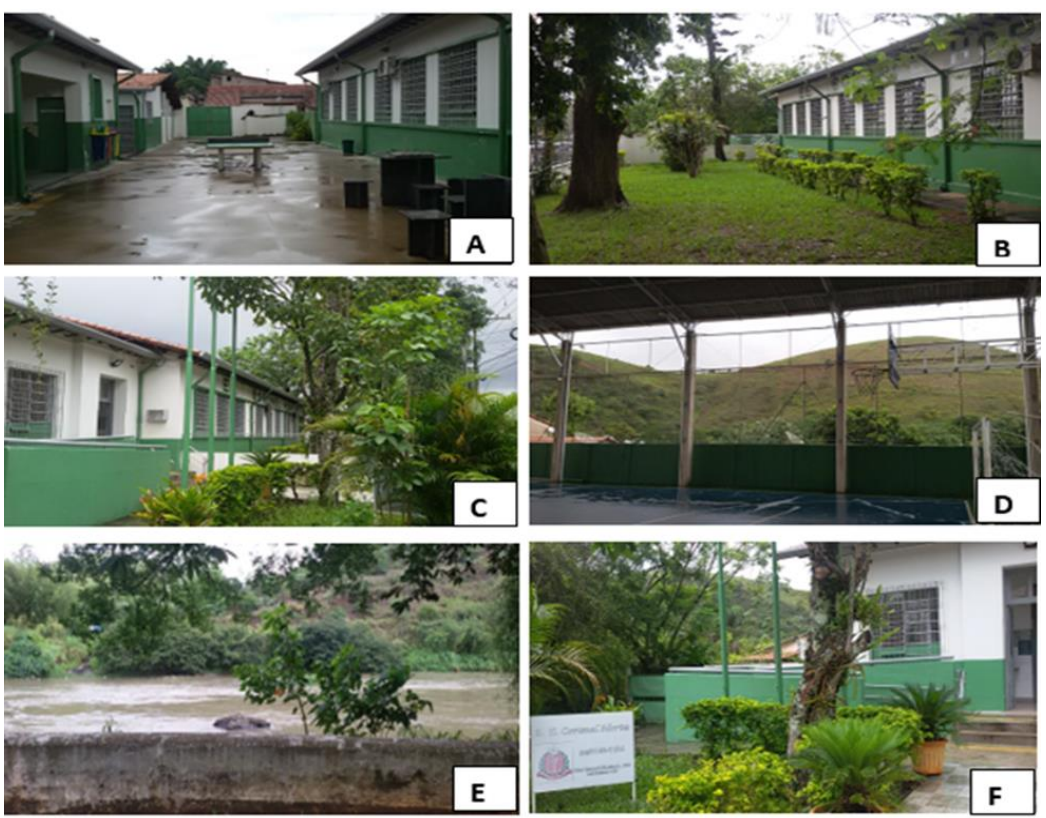

Figura 1: Unidade Escolar EE "Coronel Horta" - Lavrinhas - SP. Vista da frente do prédio da escola (B, C e F), Vista do Pátio (A e D) e Vista do rio Paraíba do Sul ao fundo da unidade escolar (E).Fonte : Autores, 2020.

Lavrinhas é uma cidade localizada ao leste do Estado de São Paulo, conhecida como Vale Histórico, distante cerca de $230 \mathrm{~km}$ da cidade de São Paulo, conforme Figura 2. A cidade é considerada o circuito de águas da região, que é composto por várias cachoeiras e rios encantadores de águas cristalinas, balneários e montanhas, conforme o que mostra a Figura 02. Sua economia, atualmente, é baseada na pecuária e agricultura e no setor turístico ecológico devido sua localização e visual. Em 2017, a cidade passou a fazer 
parte do mapa do Turismo Brasileiro, compondo também a Região Turística Picos da Mantiqueira.

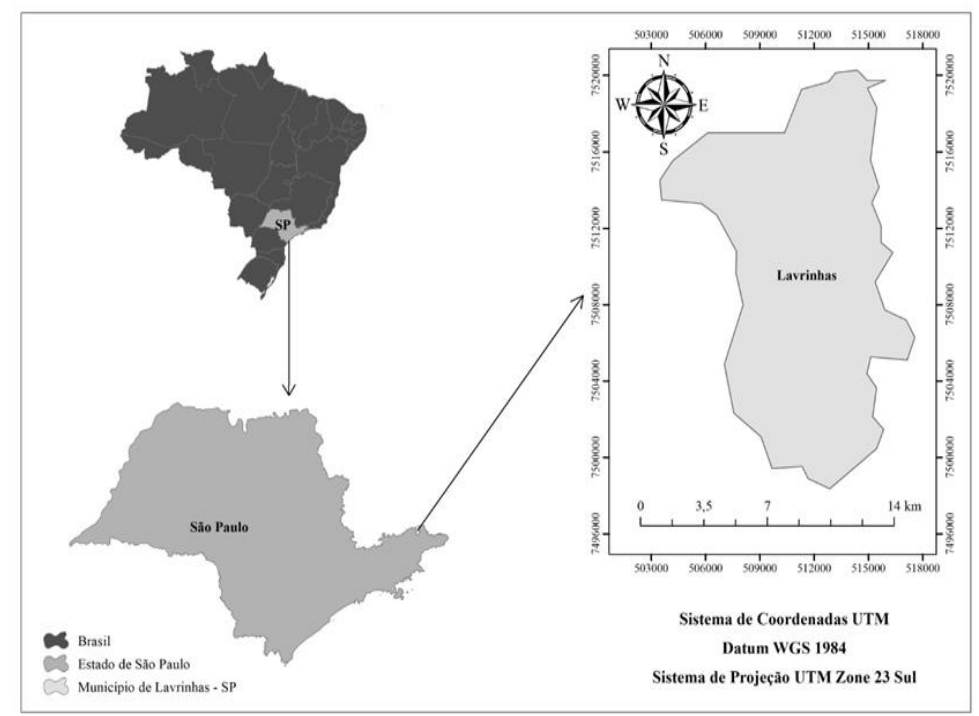

Figura 2: Localização do município de Lavrinhas, estado de São Paulo e local da pesquisa.

Fonte: Autores, 2020.

Esta unidade escolar possuía, no ano de 2020, quando foi realizada a pesquisa, três segmentos, a saber: Médio (do $1^{\circ}$ ao $3^{\circ}$ ano), no turno da manhã; Ensino Fundamental II (do $6^{\circ}$ ao $9^{\circ}$ ano), no turno da tarde; e Educação de Jovens e Adultos - EJA (do $1^{\circ}$ ao $3^{\circ}$ ano do EM).

Para o desenvolvimento da presente pesquisa, foram selecionados alunos do segmento Ensino Fundamental II (do $6^{\circ}$ ao $9^{\circ}$ ano), totalizando quatro (04) turmas da referida unidade escolar.

A escolha desse grupo de alunos para participar do referido projeto, baseou-se no critério de maior possibilidade de intervenção interdisciplinar, pois é a partir do ensino Fundamental II (6으 - 9aㅡ ano que os alunos passam a ter contato com mais professores. Assim, esses estudantes começam a se tornar mais independentes na divulgação de ações protagonistas, passam a estudar por meio dos projetos interdisciplinares que são desenvolvidos dentro das unidades escolares e, dessa forma, iniciam o desenvolvimento de sua autonomia e senso de reponsabilidade.

O jogo que foi desenvolvido trata-se de um quiz, elaborado com perguntas sobre diversas temáticas ambientais. Houve a preocupação de propor questões contextualizadas que apresentassem situações que poderão ser vivenciadas pelos alunos em seu cotidiano. Para cada pergunta proposta, apenas uma resposta deveria ser selecionada. Após fornecer uma resposta, o jogo apresentava um feedback que descrevia se o aluno escolheu ou não a resposta correta, inclusive, informando qual era a resposta correta.

Inicialmente, foi feito um convite destinado a todo o segmento descrito e os alunos que manifestaram interesse em participar, foram inseridos no banco 
de dados do jogo educativo. No total, foram inscritos 35 alunos, sendo que 20 utilizaram o jogo em duas etapas

O jogo foi constituído por dez (10) questões que abordavam o eixo Recursos Naturais (RN), dez (10) questões sobre Preservação Ambiental (PA) e dez (10) questões a respeito de Ações Sustentáveis (AS), totalizando 30. As questões foram distribuídas por série de acordo com o Currículo Paulista da Secretaria de Educação do Estado de SP (SEE-SP, 2012).

Este artefato computacional trata-se de uma Aplicação Web, desenvolvida em MySQL, que é, atualmente, um dos sistemas de gerenciamento de banco dados mais utilizados e populares. A versão web foi programada utilizando as seguintes linguagens de programação: HTML (Versão para editor de hipertextos), PHP (Linguagem livre embutida em páginas de internet), CSS (Linguagens para formatação de páginas de internet) e Java script (Interação entre o HTML e interpretação do navegador utilizado).

O jogo está disponível em um site particular com custos operacionais pagos anualmente, em uma máquina virtual com o sistema operacional Linux de 100 GB disponível para armazenamento.

Neste jogo educativo, os alunos foram cadastrados no Banco de Dados por meio do seu RA e senha pessoal. A Figura 3 apresenta a tela de cadastro do Banco de Dados e tela inicial do jogo educativo.
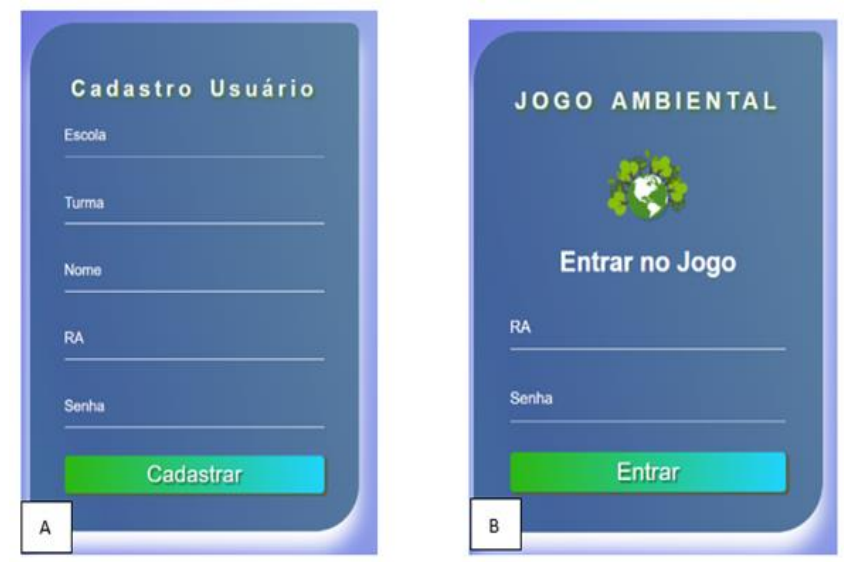

Figura 3: Tela de dados cadastrais(A); Tela de dados do usuário (B).

Fonte: Autores, 2020.

Para obter informações que apresentassem evidências acerca da efetividade do jogo educativo, colheu-se relatos de alguns alunos por meio das seguintes perguntas:

$\checkmark$ Você entendeu as regras do jogo com facilidade? Ele é fácil de ser utilizado?

$\checkmark$ Você achou o jogo interessante e divertido?

$\checkmark$ O que você aprendeu após utilizar este jogo? 
Estes relatos, obtidos durante a segunda etapa do jogo educativo, foram transcritos e avaliados por meio da técnica de Análise de Conteúdo que consiste em estabelecer inferências com a finalidade de identificar proposições ao relacionar os relatos com o arcabouço teórico que subsidia a pesquisa (BARDIN, 2010).

\section{Resultados e Discussões}

A escolha dos temas do jogo educativo iniciou-se durante as aulas de Tecnologia e Inovação em fevereiro de 2020, com os alunos do EF II da unidade escolar. Em março de 2020, devido a pandemia de COVID- 19 e regulamentação do Governo do Estado de SP e SEE-SP (DECRETO 64891 30/03/2020 - GOVERNO ESTADO SP), ocorreu a suspensão das atividades presenciais. Neste momento, a escolha dos temas e aplicação do jogo ocorreram de forma remota.

Segundo Dias (2004), a sensibilização pode ocorrer por meio de atividades simples e cotidianas vivenciadas pelos educandos. Sendo assim, foi realizada uma atividade online, em que se solicitou aos alunos do EF II a elaboração de um desenho que representasse o seu entendimento acerca da EA, com o objetivo de aproximá-los desta temática que seria abordada posteriormente no jogo educativo aplicado, conforme a Figura 4. Ressalta-se que estes desenhos foram utilizados para o desenvolvimento da interface do jogo educativo, como forma de envolver os alunos no processo de concepção deste artefato computacional.

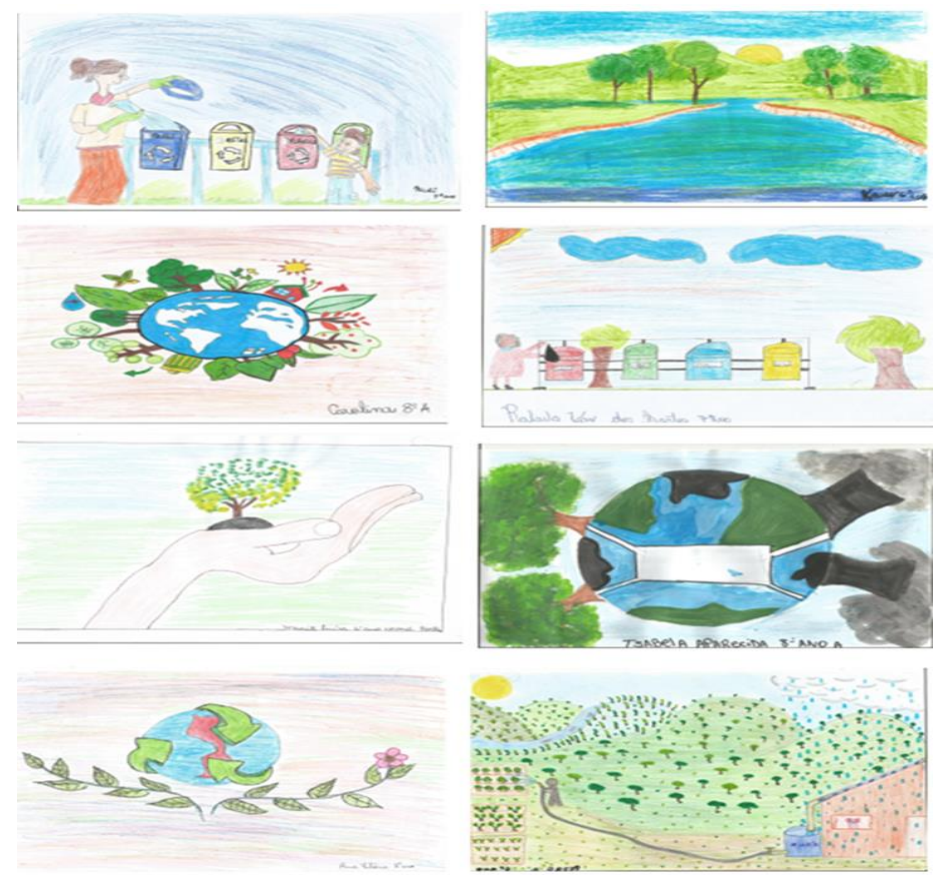

Figura 4: Desenhos desenvolvidos pelos alunos EF II sobre EA.

Fonte: Autores, 2020. 
Souza et al. (2013), enfatizam a importância da Educação Ambiental nas escolas para se formar cidadãos conscientes, por meio de um ensino ativo e participativo que permita o aprendizado. Com este propósito, o referido jogo educativo foi aplicado em duas etapas, respectivamente: a primeira etapa em 19/11/2020 e a segunda etapa em 26/11/2020. Ambas aconteceram de forma remota na plataforma Google Meet. e são descritas a seguir:

$\checkmark$ Primeira etapa de aplicação: foram apresentados os objetivos de aprendizagem desta atividade extracurricular e explicou-se como utilizar o jogo. Falou-se sobre a importância do meio ambiente. Nesse momento, os alunos envolvidos tiveram o primeiro contato com o jogo educacional, ao jogá-lo pela primeira vez.

$\checkmark$ Segunda etapa de aplicação: foram apresentados os resultados armazenados no Banco de Dados do jogo digital. Considerando estes resultados, realizou-se uma aula interativa sobre os tópicos abordados no jogo buscando, inclusive, apresentar as respostas corretas para as questões com respostas incorretas da Primeira etapa. Em seguida, os alunos jogaram pela segunda vez.

A Tabela 1 apresenta os resultados por série/ano nas duas etapas de aplicação do jogo ambiental. Constatou-se melhoria na pontuação obtida nos três eixos, com destaque para o eixo Recursos Naturais.

Tabela 1: Resultado por série, do $6^{\circ}$ ao $9^{\circ}$ ano, nas etapas do Jogo Ambiental.

\begin{tabular}{|c|c|c|c|c|c|c|c|}
\hline \multirow{2}{*}{$\begin{array}{l}\text { Eixos } \\
\text { Temáticos }\end{array}$} & \multicolumn{3}{|c|}{ 1' ETAPA } & \multicolumn{3}{|c|}{$2^{\mathrm{a}}$ ETAPA } & \multirow{2}{*}{$\begin{array}{c}\text { Melhoria do } \\
\text { conhecimento }\end{array}$} \\
\hline & ANO/SERIE* & ACERTOS & ERROS & ANO/SERIE* & ACERTOS & ERROS & \\
\hline \multirow{4}{*}{$\begin{array}{l}\text { Ações } \\
\text { Sustentáveis }\end{array}$} & $6^{\circ}$ & $80 \%$ & $20 \%$ & $6^{\circ}$ & $86 \%$ & $14 \%$ & $06 \%$ \\
\hline & $7^{\circ}$ & $75 \%$ & $25 \%$ & $7^{\circ}$ & $85 \%$ & $15 \%$ & $10 \%$ \\
\hline & $8^{\circ}$ & $72 \%$ & $28 \%$ & $8^{\circ}$ & $93 \%$ & $07 \%$ & $11 \%$ \\
\hline & $9^{\circ}$ & $78 \%$ & $22 \%$ & $9^{\circ}$ & $96 \%$ & $04 \%$ & $18 \%$ \\
\hline \multirow{4}{*}{$\begin{array}{l}\text { Preservação } \\
\text { Ambiental }\end{array}$} & $6^{0}$ & $71 \%$ & $29 \%$ & $6^{\circ}$ & $84 \%$ & $16 \%$ & $13 \%$ \\
\hline & $7^{0}$ & $70 \%$ & $30 \%$ & $7^{0}$ & $85 \%$ & $15 \%$ & $15 \%$ \\
\hline & $8^{\circ}$ & $70 \%$ & $30 \%$ & $8^{\circ}$ & $93 \%$ & $07 \%$ & $13 \%$ \\
\hline & $9^{\circ}$ & $86 \%$ & $14 \%$ & $9^{\circ}$ & $96 \%$ & $04 \%$ & $10 \%$ \\
\hline \multirow{4}{*}{$\begin{array}{l}\text { Recursos } \\
\text { Naturais }\end{array}$} & $6^{0}$ & $61 \%$ & $39 \%$ & $6^{\circ}$ & $89 \%$ & $11 \%$ & $28 \%$ \\
\hline & $7^{0}$ & $70 \%$ & $30 \%$ & $7^{0}$ & $90 \%$ & $10 \%$ & $20 \%$ \\
\hline & $8^{\circ}$ & $67 \%$ & $33 \%$ & $8^{\circ}$ & $93 \%$ & $07 \%$ & $26 \%$ \\
\hline & $9^{\circ}$ & $76 \%$ & $24 \%$ & 9o & $96 \%$ & $04 \%$ & $20 \%$ \\
\hline
\end{tabular}

Fonte: Autores, 2021.

Em relação à primeira etapa, no eixo temático 'Ações Sustentáveis', a questão que obteve o maior número de acertos abordou a relação entre preservar e inovar. Já, a questão com maior número de erros abordou o conceito de desenvolvimento sustentável. No eixo 'Preservação Ambiental', a questão sobre o tema desmatamento da Amazônia -assunto que estava na 
mídia em novembro de 2020 - apresentou maior número de acertos e a questão sobre o conceito de bacia hidrográfica, apresentou maior número de erros. No eixo 'Recursos Naturais', a questão que obteve maior número de acertos tratou sobre a composição da água e aquela com maior número de erros, sobre a forma como a água é encontrada.

Ressalta-se que as questões que apresentaram maior número de erros na primeira etapa foram respondidas, corretamente, pela maioria dos alunos (87\%), na segunda etapa.

Logo, ao analisar os resultados obtidos por meio deste jogo educativo, acredita-se que esta ferramenta apresenta potencial para subsidiar o processo de ensino-aprendizagem de conteúdos da EA (MOURA et al., 2015; PRENSKY, 2012, PINTO, 2018). A Figura 5 apresenta uma das questões deste jogo educativo como exemplo.

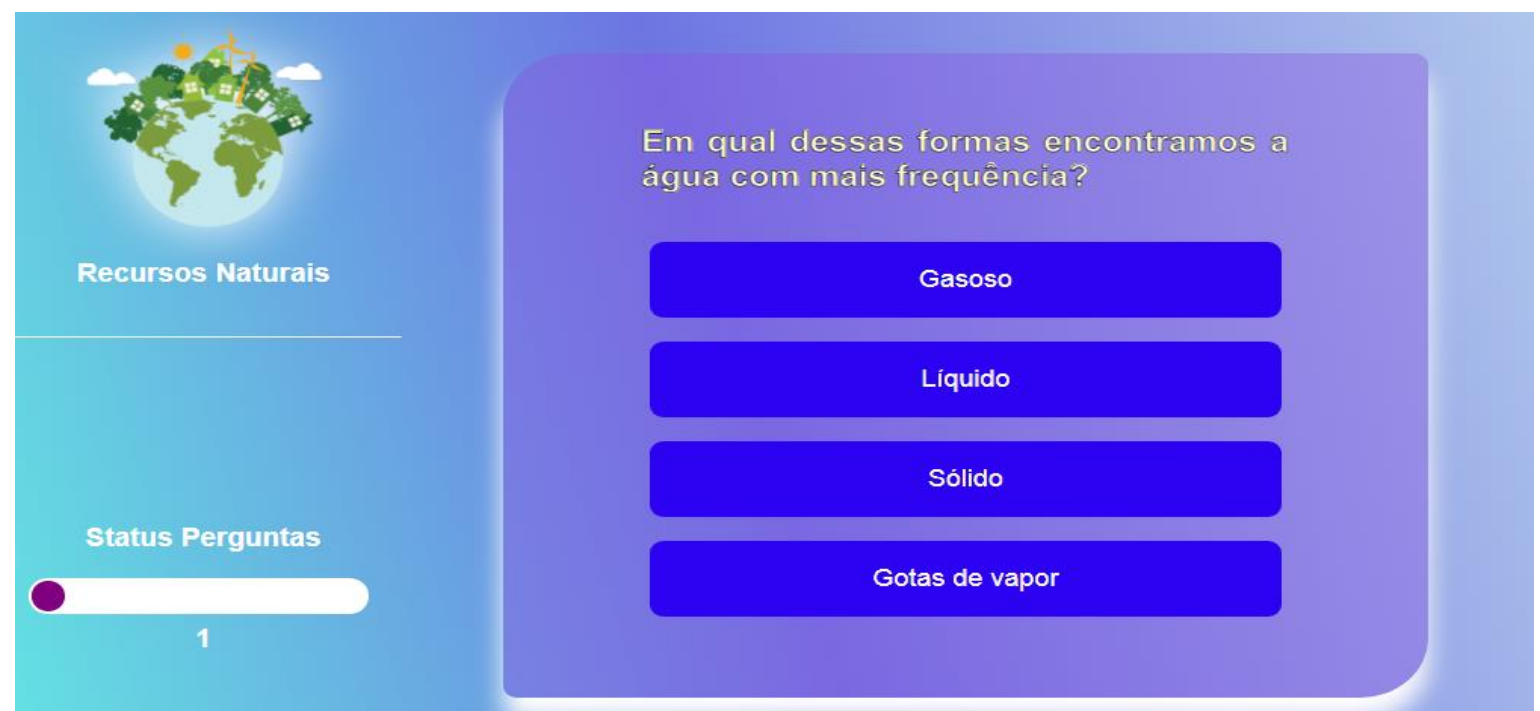

Figura 5: Exemplo de questão do jogo educativo (Quiz).

Fonte: Autores, 2021.

A avaliação do jogo digital também foi realizada por meio de relatos dos alunos que participaram dessa atividade extracurricular.

Segundo Gunther (2003), a análise de relatos consiste em coletar e avaliar a percepção dos indivíduos envolvidos no fenômeno investigado com o intuito de se obter respostas para determinados questionamentos por meio do parecer destes indivíduos.

Os relatos foram obtidos no final da segunda etapa de aplicação do jogo educativo por meio das três perguntas mencionadas anteriormente que buscaram identificar: nível de usabilidade do jogo educativo; nível de interesse pelo jogo; efetividade do jogo como método de ensino. Seguem alguns relatos obtidos: 
$\checkmark$ Nível de usabilidade do jogo digital:

Buscou-se compreender, de acordo com as percepções dos alunos, se este jogo era de fácil utilização e se suas regras estavam claras e objetivas durante o processo de jogar: "Sim eu entendi bem as regras do jogo ambiental, o professor responsável explicou tudo com bastante detalhe em uma aula online. Esse jogo foi fácil jogar, mas no começo eu tive medo de errar as perguntas, e quando comecei a jogar eu entendi melhor" (A2).

$\checkmark$ Nível de interesse pelo jogo digital como método de ensino:

Buscou-se identificar se o jogo educativo despertou o interesse dos alunos no processo de ensino-aprendizagem dos conteúdos de EA: "Eu achei o jogo muito interessante, tem muitas cores e sons, que fazem a gente entender cada tema do jogo. Também achei o jogo bem divertido, pois a gente aprende coisas do meio ambiente e como cuidar da água brincando de jogar pelo computador" (A6).

$\checkmark$ Efetividade do jogo digital como método de ensino

Buscou-se compreender se o jogo educativo contribuiu para o aprendizado de determinados conteúdos de EA - o que já foi constatado na fase de aplicação. No entanto, buscou-se colher relatos que evidenciassem esta situação, além da pontuação obtida pelos alunos ao fazerem uso do jogo educativo: "Eu adquiri novos conhecimentos sobre a Educação Ambiental e passei a me preocupar com a natureza ainda mais, e vi que Educação Ambiental não se refere somente as paisagens totalmente da natureza, mas sim alguns pontos urbanos também. E sobre o desenvolvimento sustentável também eu aprendi muitas coisas. (A1).

\section{Considerações Finais}

A EA, além de ser uma temática obrigatória para a educação básica, trata-se de uma necessidade, pois somente por meio da compreensão acerca da importância da conservação dos recursos naturais, poderá ocorrer a sensibilização e a mudança de comportamento requerida para se atender aos princípios do desenvolvimento sustentável.

Diante deste cenário, este estudo buscou propor uma ferramenta pedagógica para promover a EA no ensino básico. Ao final, os objetivos de pesquisa elencados foram atendidos. Por meio de ferramentas tecnológicas, métodos de análise e desenvolvimento de sistemas e da fundamentação teórica acerca dos conteúdos de EA que necessitam ser abordados para os alunos do Fundamental II, foi possível desenvolver um quiz que se apresenta como uma metodologia de ensino eficaz para a EA.

Ainda nesta investigação, constatou-se que os educandos visualizam os 
significativa e ativa. Após a aplicação do jogo educativo em duas etapas, evidenciou-se uma melhoria no desempenho dos alunos, ou seja, por meio da avaliação dos erros é possível aprender, principalmente, quando o jogo e o professor apresentam as justificativas que embasam as questões corretas ou incorretas. Neste momento, o docente atua como mediador/facilitador da aprendizagem e o aluno, como o principal responsável pelo seu aprendizado. Logo, os jogos educativos digitais apresentam potencial como método para o ensino de diversos conteúdos da educação básica, além daqueles referentes à EA, por priorizarem os princípios da aprendizagem significativa e ativa. Acrescenta-se que os relatos obtidos se apresentam como importantes evidências acerca da efetividade do quiz desenvolvido quando ao seu propósito formativo.

Entretanto, destacam-se algumas dificuldades que podem impedir o uso deste recurso nas escolas, como a ausência de recursos tecnológicos (computadores e conexão de internet de bom desempenho) e a qualificação docente para a utilização deste artefato computacional durante as aulas.

Como pesquisa futura, sugere-se que este jogo seja aplicado em outras escolas, envolvendo outros grupos de alunos com a finalidade de aprimorá-lo. Sugere-se ainda, conforme mencionado anteriormente, o seu uso para a abordagem de outros conteúdos da educação básica.

\section{Referências}

ALVES, L. Games e educação: desvendando o labirinto da pesquisa. Revista de Educação Contemporânea, Salvador, v.22, n.40, p.177-186, 2013.

BACICH, L.; MORAN, J. Metodologias áticas para uma educação inovadora: uma abordagem teórico prática. Porto Alegre: Penso, 2018.

BARDIN, L. Análise de conteúdo. 4aㅡ Ed. Lisboa: Edições 70, 2010.

BRAGA, M. R. S.; COSTA, R. G. Usando jogos digitais educacionais para apoiar o processo Ensino-aprendizagem em escolas Fundamentais brasileiras. Revista de Ciência, Tecnologia e Inovação, v. 12, n. 2, p. 26-35, abr. 2017.

COUTINHO, I.; ALVES, L. Os desafios e possibilidades de uma prática baseada em evidências com jogos digitais nos cenários educativos. In: ALVES, L.; COUTINHO, I. Jogos digitais e aprendizagem: fundamentos para uma prática baseada em evidências. Campinas: Papirus, 2016.

CUNHA, A. H. N.; MOTA, T. R. Formação crítica acerca do meio ambiente e conhecimento sobre Educação Ambiental. In: IX Congresso Brasileiro de Gestão Ambiental, São Bernardo do Campo. Anais[...]. São Bernardo do Campo: Instituto Brasileiro de Estudos Ambientais, 2018. p.01-07.

DIAS, G. F Educação Ambiental: princípios e práticas. São Paulo: Gaia. 2004. FERNANDES, K. T.; LUCENA, M. J. N. R.; ARANHA, E. H. S. Uma experiência na criação de Game Design de Jogos Digitais Educativos a partir do Design Thinking. Renote, v.16, n. 1, 2018. 
FERREIRA, W.C.; OLIVEIRA, C.A. O Jogo Digital QuizPG nas Aulas de Matemática: possibilidades para o Ensino e Aprendizagem de Progressão Geométrica. Revista de Educação Matemática, São Paulo, v.18, 2021, p.1-20.

GOSSENHEIMER, A. N.; CARNEIRO, M. L. F.; CASTRO, M. S. Estudo comparativo da metodologia ativa "gincana" nas modalidades presencial e à distância em curso de graduação de Farmácia. Arquivos Brasileiros de Ciência e Saúde, Porto Alegre, v. 40, n.3, p. 234-240, 2015.

GODOY, A. S. A pesquisa qualitativa: tipos fundamentais. Revista de Administração de Empresas. São Paulo, v. 35, n. 3, p. 20-29, maio/jun. 1995. GUNTHER, H. Como elaborar um Relato de Pesquisa - Série: Planejamento de Pesquisa nas Ciências Sociais, no 02 . UnB, Laboratório de Psicologia Ambiental Brasília, DF. 2003.

KAMII, C.; RHETA, D. Jogos na educação: implicações da teoria de Piaget. Porto Alegre: Artmed, 2009.

KISHIMOTO, T. M. Jogo, brinquedo, brincadeiras e a educação. São Paulo, Editora Cortez: 2000.

LORO, A.R. A importância do brincar na Educação Infantil. UNIJUÍ. Santa Rosa. 2015. Disponível em: <http://bibliodigital.unijui.edu.br:8080/xmlui/ bitstream/handle/123456789/3391/Aline\%20Loro\%20TCC\%20p\%C3\%B3s\%20 banca.pdf?sequence=1>. Acesso em 26 jun. 2021.

McGONIGAL, J. A realidade em jogo: porque os games nos tornam melhores e como eles podem mudar o mundo. Rio de Janeiro: BestSeller, 2017.

MATTAR, J. Games em educação: como os nativos digitais aprendem. São Paulo: Pearson Prentice Hall, 2010.

MORAN, J. M.; MASETTO, M.; BEHRENS, M. Novas tecnologias e mediação pedagógica. 21.ed. São Paulo: Papirus, 2013.

MOURA, R. B. C. et al. Possibilidades Educacionais Ampliadas pelo Uso das Novas Tecnologias no Cenário dos Nativos Digitais. Simpósio de Pesquisa e Desenvolvimento em Computação, Cruz Alta, RS, p.1-4, 2015.

OLIVEIRA, L.; NEIMAN, Z. Educação Ambiental no âmbito escolar: análise do processo de elaboração e aprovação da Base Nacional Comum Curricular (BNCC). Revista Brasileira de Educação Ambiental, São Paulo, v. 15, n. 3, p. 36-52, 2020.

PAULA, B.; VALENTE, J. Jogos digitais e educação: uma possibilidade de mudança da abordagem pedagógica no ensino formal. Revista Iberoamericana de Educación, v. 70, n. 1, p. 9-28, jan. 2016.

PEREZ, P. L.; BOTINO, C. F. S. Quiz mediado por sistemas de resposta dos estudantes como estratégia de ensino-aprendizado. Revista da Universidade Federal Fluminense, v. 23. n.1, 2020.

PINHEIRO, A. A. S.; OlIVEIRA NETO, B. M.; MACIEL, N. M. T. C. A importância da Educação Ambiental para o aprimoramento profissional, docente e humano. Ensino em Perspectivas, Fortaleza, v. 2, n. 1, 2021. 
PINTO, A. P. Os Jogos Educativos nas práticas ambientais: um estudo na Escola Agrícola "José Cesário Mendes de Barros", Humaítá - AM. Dissertação (Mestrado profissional). Universidade Federal de Rondônia, Porto Velho, 2018.

POLLI, A.; SIGNORINI, T. A inserção da Educação Ambiental na prática pedagógica. Ambiente \& educação. Rio grande, v. 17, n. 2, p.93-101, 2012.

PRENSKY, M. Não me atrapalhe, mãe - Eu estou aprendendo! São Paulo: Phorte, 2010.

PRENSKY, M. Aprendizagem baseada em jogos digitais. São Paulo: Senac, 2012.

RAMOS, D. K.; CRUZ, D. M. Jogos digitais em contextos educacionais. Curitiba: Editora CRV, 2018.

SANTOS, P. R.; BARBOSA, D. N. F.; MOSSMANN, J. B.; CERQUEIRA, B. B.; ETGES, Y. S. Conscientização ambiental em construtos digitais de aprendizagem: a experiência do jogo 'Guardiões das Águas'. Debates em Educação, Maceió, v.12, n.27, p.593-614, 2020.

SECRETARIA EDUCAÇÃO ESTADO SÃO PAULO - SEE -SP. Currículo do Estado de São Paulo: Ciências da Natureza e suas Tecnologias. São Paulo: SEE, 2012, 2ª ed., 156p.

SILVEIRA, I. M. S.; RUAS, T. O.; ELIAS, N. F. Educação Ambiental e suas Práticas como exercício da cidadania na Escola Básica. Revista Verde Grande, v. 3, n.1, p.106-123, 2021.

SOARES, F. M. N.; NASCIMENTO, M. F. F. A produção e o uso dos jogos digitais como estratégia para a Educação Ambiental no Ensino Fundamental. Rev. Educ., Brasília, ano 43, n. 162, p. 112-124, jun./set. 2020.

SOUZA, G.S. et al. Educação Ambiental como ferramenta para o manejo de resíduos sólidos no cotidiano escolar. Revista Brasileira de Educação Ambiental, Rio Grande, v. 8, n. 2:118-130, 2013.

SOUZA, F. R. S. Educação Ambiental e sustentabilidade: uma intervenção emergente na escola. Revista Brasileira de Educação Ambiental, São Paulo, v. 15, n. 3, p.115-121, 2020.

VALENTE, J. A.; ALMEIDA, M. E. B.; GERALDINI, A. F. S. Metodologias ativas: das concepções às práticas em distintos níveis de ensino. Rev. Diálogo Educ., Curitiba, v. 17, n. 52, p. 455-478, abr./jun. 2017.

VASCONCELLO, M. S.; CARVALHO, F. G.; BARRETO, J. O. ATELLA, G. C. As Várias Faces dos Jogos Digitais na Educação. Informática na educação: teoria \& prática, Porto Alegre, v.20, n.4, ago. 2017.

VYGOTSKY, L. S. A formação social da mente: o desenvolvimento dos processos psicológicos superiores. São Paulo: Martins Fontes, 2003.

YIN, R. K. Estudo de caso, planejamento e métodos. São Paulo: Bookman, 2005. 